\title{
Do jornal impresso às telas digitais: trilhas do leitor
}

Ana Elisa Ribeiro*

Resumo: Neste trabalho, discutem-se aspectos da interação do leitor com produtos jornalísticos que simulam suas versões impressas. Os estudos do jornalismo digital levados a cabo no Brasil embasam a investigação, na qual se relata uma experiência de leitura com sete brasileiros, de idades diferentes, cuja tarefa foi navegar e ler o Jornal do Brasil Online. Para a geração de dados, foram feitas entrevistas com leitores e gravou-se em áudio o protocolo verbal das experiências de leitura. A navegação de cada usuário também foi registrada por software especializado. Após a análise dos protocolos verbais e o cotejamento com as ações na tela do computador, chegou-se a resultados que apontam para uma atividade intensa do leitor na lida com o papel e a tela, mesmo quando tem pouca experiência de leitura em ambiente digital. Conclui-se que o leitor não se deixa levar pela hibridização de linguagens, mostrando-se ora confortável ora incomodado com as propostas de leitura e interação que o jornal lhe oferece.

Palavras-chave: leitura, dispositivos tecnológicos de leitura, telas, jornalismo digital, webjornalismo.

\section{Introdução}

No ano de 2006, no Brasil, um grande jornal do estado de Minas Gerais lançava sua versão "digital” com forte campanha junto ao leitor. Tratava-se, então, de uma espécie de digitalização da versão impressa. As páginas virtuais eram exatamente como as de papel e uma programação com tecnologia Flash permitia que o leitor "folheasse" as páginas por meio de cliques. Muito embora fosse anunciado como novidade, esse tipo de produto existia desde os primeiros tempos do jornalismo na web, quando uma primeira "onda" ou "fase" da produção jornalística para a internet ofereceu ao leitor as versões online dos periódicos, ainda nos anos 1990.

* Mestre em Estudos de Linguagens do Centro Federal de Educação Tecnológica de Minas Gerais (Brasil), anadigital@ gmail.com. 
Neste trabalho, trataremos de aspectos da leitura na web, focalizando jornais que simulam suas versões impressas, cuidando de fazer lembrar ao leitor os gestos de navegação que ele aprendeu na lida com o papel. Por meio de entrevistas com uma amostra não-representativa de leitores, discutiremos aspectos que podem significar certa tipicidade da interação leitor/texto nesses displays que hibridizam linguagens.

\section{Usuários, displays, suportes e portadores de texto}

"Usuário" tem sido a alcunha do leitor que tem como uma de suas práticas ler textos (verbais, mas não apenas) utilizando telas como displays. Não raro essa tela é a do computador, mas também podem ser outras telas eletrônicas. São displays as telas de toda natureza, nas quais textos são mostrados, projetados ou revelados, assim como outdoors, painéis, rótulos em garrafas e livros. Assim, o display de um texto publicitário pode ser um outdoor; o display da notícia pode ser um televisor, um mural no corredor da escola, um folheto volante ou uma tela de telefone móvel.

Em alguma medida, displays são sinônimo de "suportes", de "portadores" ou ainda de "interfaces". Para ser interface, o display precisa cumprir a função de mediar a operação do leitor na interação com o texto. Jornais podem ser considerados interfaces na medida em que apresentam uma diagramação e uma composição multimodais ${ }^{1}$ que ajudam o leitor a percorrê-los ou a encontrar o que procura. Para ser suporte, o display precisa, segundo Teberosky e Colomer (2003), ser um objeto especialmente feito para a inscrição de texto. É o caso dos livros, dos jornais ou das revistas, que não servem a outra inscrição ou função (ao menos em sua apropriação mais comum). Já para ser um portador, o display precisa, segundo as mesmas autoras, poder acolher um texto, embora não seja primordialmente feito para essa função. Talvez fosse o caso dos primeiros telefones móveis, quando eram compreendidos como aparelhos para proporcionar comunicação falada a distância. Atualmente, muito embora sirvam para telefonar, as telas de celulares permitem outras atividades, inclusive textuais, de importância concorrente em relação a sua serventia inicial.

Dentro dessa lógica, livros, por exemplo, não são interfaces, mas são displays para textos, muito afiliados à linhagem dos suportes e distantes dos portadores (que o são apenas eventualmente, por força de alguma apropriação surpreendente). Se livros são suportes, o layout da página é a interface, pois é o projeto de design que apresenta ao leitor uma proposta de trilha para a leitura. Isso não quer dizer que o leitor caminhe obedientemente por ela.

\footnotetext{
${ }^{1}$ Existem várias abordagens teóricas para o tratamento do texto como objeto semiótico. Em outros trabalhos, empregamos a gramática visual de Kress e Van Leeuwen, especialmente nas obras de 2001 e 2006, para tratar da multimodalidade. Para esses autores, multimodalidade é o "uso de diversas modalidades semióticas no design de um produto ou evento semiótico, juntamente com a forma particular como essas modalidades são combinadas" (2001: 20). As modalidades são "recursos semióticos que permitem a realização simultânea de discursos e tipos de (inter)ação" (Kress e Van Leeuwen, 2001: 21-22). Em artigo de 1998, os autores tratam especificamente do layout de jornais impressos. Abordaremos os jornais online, neste trabalho, de outra perspetiva (a genealógica, de Bolter e Grusin, 2000), muito embora sempre consideremos o jornal um objeto semiótico complexo.
} 
Este debate beira a distinção entre objetos que podem muito bem ser híbridos ou remediados (Bolter e Grusin, 2000): é possível se afirmar que uma tela de computador seja (apenas ou primordialmente) um suporte? É preciso lembrar que os projetos tecnológicos nem sempre se tornam o que foram inicialmente programados para ser. Os inventores do computador solucionavam um problema de matemática ou um problema de comunicação? Os inventores da internet resolviam questões de transmissão de dados entre máquinas ou entre pessoas? Nosengo (2008) mostra que as tecnologias sofrem apropriações surpreendentes, conforme caminhos complexos e imprevisíveis.

Outra palavra que volta à tona é plataforma. Moraes (2008), citando Richard Sennett, explica que as plataformas são um elemento fortemente ligado à padronização. Carros, por exemplo, costumam ser apenas superficialmente diferenciados, embora sejam feitos, por questões econômicas e tecnológicas, sobre as mesmas plataformas. A palavra tem sido aplicada às questões de texto, especialmente para o caso de displays digitais.

Uma interface pode ser planejada para funcionar em determinado display, porém com o objetivo de se parecer com outro display. Este é o caso que quero mostrar, não apenas em sua operação (foco no objeto), mas em sua relação com o leitor (foco no usuário, como dizem os engenheiros de software). Na falta de palavra melhor, emprego "simulação" para nomear os jornais online que projetam versões parecidas com seus displays e suas interfaces impressas. Alguns autores, não poucos, chamam a isso de "metáfora do impresso" 2 . No caso que queremos mostrar, as empresas jornalísticas lançam e mantêm uma versão online de seus jornais com características visuais que remetem ao jornal impresso, no entanto, não o são. Por que se parecem? E por que não são? Porque uma camada do design é como aquela que se espera do jornal impresso, mas a programação é de jornal digital; a aparência é de jornal impresso, mas a mediação da tela e do mouse distancia o leitor do objeto, isto é, o contato com a tela é anterior a um contato jamais possível com o que se desenha dentro dela. Mas a tela sozinha não é suficiente para que um texto seja mostrado nela. É necessário ter um software que leia (ou permita ler) aquela programação. Sem mais essa mediação, não se pode acessar o texto, nem mesmo o simulado (e qual deles não o é, nas telas?). A essa hibridização entre tecnologias e gestos do ambiente digital com a estética do impresso chamamos "transposição"3 (Mielniczuk, 2001; 2003).

Telas são displays na medida em que mostram as composições preparadas para serem lidas. Computadores, que têm telas, são displays de diversos tipos de texto, sejam eles transmitidos via web ou não. Garrafas podem ser displays, assim como camisetas

\footnotetext{
${ }^{2}$ Palácios (2002), Silva Júnior (2001) e Suzana Barbosa (2001) mencionam Melinda McAdams, no texto "Inventing an Online Newspaper", de 1995, como a fonte da expressão "modelo da metáfora", que descreve um modelo de jornalismo baseado em suportes mediáticos anteriores. No Brasil, tornou-se corrente, também, a expressão que mencionamos aqui. ${ }^{3}$ A palavra vem sendo empregada nos estudos de jornalismo digital no Brasil para descrever um periódico que mantém uma versão online que se assemelha à sua versão impressa, demonstrando pouca preocupação em utilizar os recursos e as possibilidades que o ambiente digital permite. Em português brasileiro, o termo é exatamente "transposição", cujo sentido vem de "transpor", passar de um meio a outro, conforme acepções dos dicionários Houaiss (2001) e Ferreira (2004).
} 
e peles tatuadas. No entanto, peles não são suportes, embora possam ser portadoras e, eventualmente, interfaces.

O design gráfico, uma espécie de engenharia de leitura, planeja o tamanho, a fonte, a aparência, as colunas, o tipo de papel, a relação entrelinha/mancha, assim como incorpora ao suporte tecnologias como sumário, primeira página em mosaico e numeração. O design web vem tentando fazer o mesmo, com base no que se conclui ser mais adequado ao novo display e à nova relação entre ele e o leitor. $\mathrm{O}$ jornal não funciona da mesma forma no display que mostra uma imagem digital na tela. No entanto, é dele que se faz uma simulação, num mise en abyme de displays, interfaces e suportes. Um jogo de espelhos que quer fazer funcionar um folhear precedido de um clicar, que é, necessariamente, precedido de um software e de uma programação que permitam isso.

Considerando-se uma história de longa duração (Chartier, 2001), nota-se que os responsáveis pela confeção de objetos de ler, de alguma forma o fazem conforme um aprendizado da relação entre seus produtos e o leitor. Enquanto isso, não menos rapidamente, o leitor trata de aprender a ler textos em novos dispositivos. Ao contrário do que sugerem certos discursos sobre a leitura, a aprendizagem de como fazer e a de como "consumir" não ocorrem de forma independente, como se produtores estivessem muito adiante de leitores (ou ao revés). São interdependentes, "reguladores” entre si, “evoluindo" em uma medida que não chega a estagnar nenhum dos dois lados, confluindo ambos no elemento que realmente interessa: a interação.

\section{A interface do jornal}

O jornal, tal como o conhecemos, nasce de práticas do impresso mais antigas, nomeadamente o livro, a mãe de todas elas. É natural, portanto, que tenha tido, de início, a aparência de um códice e a narrativa verbosa que lhe era ajustada. As técnicas de impressão ainda não permitiam a reprodução de imagens. E era assim que o produtor sabia fazer, embora tudo estivesse se reacomodando. Era a narrativa que o leitor podia ler, também em permanente acomodação. Zamith (1999: 6) não duvida: "Os leitores/consumidores de jornais estão progressivamente a mudar os seus hábitos.” E sempre estiveram. Não há razões para se pensar (e menos ainda para afirmar) que isso (ajustar-se) só tenha ocorrido ao leitor de umas décadas para cá.

Manter o olhar sobre o leitor brasileiro é importante, dado que temos nossas particularidades. Os primeiros jornais oficiais e livros só puderam ser impressos no Brasil em 1808. Ao contrário do que se diz hoje, Pina lembra que

era fácil ler um jornal: suas folhas se dobravam, era pouco volumoso, podia ser guardado até nas algibeiras. Podia ser lido na esquina, compartilhado por muitas pessoas. O jornal incluía, assim, os trânsitos cotidianos oitocentistas em suas possibilidades de apropriação, as quais já estavam previstas e configuradas em sua materialidade, em sua forma. (Pina, 2005: 1) 
Destaque-se o final da citação: as "possibilidades de apropriação" do jornal já estavam "previstas e configuradas em sua materialidade". Que objetos escapam a isso? Os designers parecem dar a esse tipo de "previsão" de uso o nome de affordances $^{4}$. Vez ou outra o usuário surpreende o inventor, fazendo com o objeto o que ninguém imaginara no projeto. No entanto, os próprios objetos costumam sugerir seus usos e suas possibilidades.

O jornal jamais foi dado a uma leitura linear, fosse ele parecido com o livro ou não. No século XIX ou no XXI, a justaposição de ofertas e a tentativa de envolver o leitor não parecem dirigidas a um tolo obediente. Era (e é) preciso se esforçar na produção editorial porque o leitor é difícil. Se os objetos nos vão fazendo propostas (a nós, leitores), vamos aprendendo a reagir com outras propostas. $\mathrm{Na}$ mão inversa, está o jornal aprendendo com o leitor a se configurarem, porque nenhum dos dois "fala" sozinho. Chartier (2001: 214) afirma: "Seja lá o que for, ler é uma prática criativa que inventa significados e conteúdos singulares, não redutíveis às intenções dos autores dos textos ou dos produtores dos livros. Ler é uma resposta, um trabalho (...)." No mesmo texto, Chartier faz uma pergunta inquietante: "Como poderemos considerar, ao mesmo tempo, a irredutível liberdade dos leitores e as coerções que têm por objetivo reprimir essa liberdade?” (Chartier, 2001: 214). O trecho faz recuar um pouco nosso excessivo encantamento pelas tecnologias digitais. Lembra o historiador: "É fundamental lembrar que nenhum texto existe fora do suporte que lhe confere legibilidade; qualquer compreensão de um texto, não importa de que tipo, depende das formas com as quais ele chega até seu leitor". As configurações influem na leitura, mas as práticas do leitor influem nas configurações.

Para Chartier (2001), existem "aparatos" que ajudam um texto a se propor ao leitor: aqueles ligados às estratégias de escrita do texto e aqueles estabelecidos pela "manufatura do livro ou da publicação, produzidos por decisão editorial ou através de processos industriais", ou seja, a produção de uma publicação carrega mais do que texto e mais do que técnica. Ainda no tempo das primeiras edições de livros de bolso, Chartier recupera uma história hoje familiar: "Os leitores dessas edições populares (...) liam de um jeito aparentemente descontínuo e fragmentário, que se acomodava às lacunas e incoerências" (Chartier, 2001: 225). Por onde andavam os textos lineares, que os leitores seguiam disciplinadamente? Atualmente, eles são parte de um discurso sobre as tecnologias da leitura (talvez, hoje, um discurso hegemônico). Não se lê de qualquer jeito em todo lugar, nem do mesmo jeito em qualquer lugar, há um "ajustamento de leitura" que o leitor "aciona" assim que começa a interação. Há, de lado a lado, uma influência, embora, no caso dos objetos impressos e dos digitais (também), assíncrona (diferida, como preferem alguns). Chartier (2001: 235), citando Hoggart, conclui pela "autonomia criativa do leitor diante dos mecanismos que tentam controlá-lo" 5.

\footnotetext{
${ }^{4}$ Embora a palavra tenha ficado conhecida após os estudos de J. J. Gibson sobre percepção visual, nossa abordagem se identifica com os trabalhos em design, especialmente os de Norman (1999; 2006), para quem há affordances reais e percebidas, que sugerem ao leitor/usuário a interação com um objeto. No Brasil, cunhou-se o termo "propiciamento" para traduzir o termo em inglês, mas a palavra original é mais corrente.

${ }^{5}$ Silva Júnior (2001: 4) define a forma de organização do jornal em editoriais como uma dessas tentativas. Esse "arranjo clássico visa, de maneira bastante eficiente, a orientar o modelo de exploração do leitor segundo uma ordem de problemas relativos ao ambiente urbano e mundial em que está imerso".
} 
Na produção jornalística atual, um dos problemas que emergiram após a invenção do computador é como fazer jornalismo para a web. Geralmente, a questão está concentrada no "como". Essa preocupação com os modos de fazer gera uma série de trabalhos descritivos ou premonitórios. Canavilhas (2003) estava perplexo porque afirmava ser

um completo desperdício tentar reduzir o novo meio a um simples canal de distribuição dos conteúdos já existentes. Olhar para o actual jornalismo online é algo semelhante a imaginar a transmissão de um telejornal onde alguém lê simplesmente um jornal frente a uma câmara. (Canavilhas, 2003)

O autor estava também preocupado com o "usuário", ou melhor, com

as competências que o leitor deverá ter para conseguir descodificar conteúdos multimédia. A introdução de uma nova linguagem implica o domínio de novas competências narrativas, linguísticas, iconográficas e estéticas, o que, provavelmente, vai levar algum tempo. (Canavilhas, 2006: 4)

E esse tempo será suficiente para o desenvolvimento de ambos os lados. Caso contrário, estacionaremos em algum ponto onde a interação estará no vácuo. As competências citadas pelo pesquisador são operacionais: "detectou-se que o facto das palavras linkadas não aparecerem sublinhadas, por exemplo, faz com que os utilizadores não sigam esses mesmos links" ou "a transformação do cursor do rato numa mão ainda não é associado a uma zona interactiva”. Pois o que era esperado? Se os links, até há bem pouco tempo, estiveram sempre sublinhados e o leitor os aprendeu assim, é isso o que ele espera. No entanto, não quer dizer que não possa se reajustar. Assim como aprenderá que o ícone da mão é o índice de uma zona clicável e substitui a sublinha. Essas aprendizagens são inexoráveis, bastando algum contato continuado com novos objetos que façam sentido.

A mudança dos jornais também é balística, mas guarda em si o passado. Silva Júnior (2001: 2) fala do "corriqueiro" fato de que "veículos online dividem o espaço virtual segundo uma lógica baseada em editorias, cadernos, matérias especiais, etc.”. Esse é o "modelo em metáfora" a que os pesquisadores se referem, quando a tecnologia muda ("dos átomos em bits”), mas se mantém "boa parte da sua função simbólica agregada à nova interface”. Em outras palavras, muito bem cosidas, trata-se da "coexistência de uma possibilidade com um limite". Não apenas do ponto de vista de quem faz, mas também do de quem lê. Umas mídias estão, portanto, genealogicamente ligadas a outras, como descrevem Bolter e Grusin (2000).

\section{Transposição e fases do jornalismo na web}

A “transposição" nos tem seduzido nos estudos do jornalismo na internet pelo menos desde 2003, quando lemos os primeiros debates sobre os modos de fazer jornalismo para ambiente digital. Vários autores têm se dedicado à proposição de "fases”, "etapas" ou "gerações" dos modos de produção do jornalismo na web. De outra parte, 
temos nos dedicado (e mais pesquisadores) à compreensão de outro ângulo do mesmo problema: a relação do leitor com jornais em novos ambientes. Do ponto de vista político-ideológico, não se pode afirmar, com tanta tranquilidade, que os norte-americanos do século XX tenham praticamente reinventado o leitor e o turbinado com máquinas que escavam "novos” horizontes interativos.

Nos estudos de comunicação no Brasil, a maioria das investigações está centrada na produção jornalística, às vezes na produção técnica e nas mudanças que ela sofreu após a chegada dos computadores às redações ou depois da consciência das possibilidades do ambiente digital. As mediações têm sido, na maior parte das pesquisas, mais deslindadas do que as pessoas. Mielniczuk (2004) admite a importância de estudar o leitor no webjornalismo, no entanto seu discurso enfatiza a necessidade de "rupturas" na produção, na tentativa de "firmar" uma nova modalidade de jornalismo que seja uma “opção singular e com atrativos diferenciados”. Os pressupostos quanto ao jornalismo impresso estão todos aí. Natansohn (2007), que está atenta à pesquisa em leitura, dá exemplos de Nielsen ou do Instituto Poynter, nos Estados Unidos, que têm sido pródigos em abordagens que se transformam em paradigmas de diretrizes estandardizantes para produtores e programadores. Sobre as pesquisas do Poynter, Natansohn (2007: 5) alerta: “Contudo, seus dados não podem ser generalizados para o resto da população e, ainda, não leva em conta mais do que o olhar do usuário (literalmente falando), supondo que olhar é sinônimo de ler." A mesma autora afirma haver um "vazio" nas pesquisas sobre outros aspectos da recepção (entendida como mais do que apenas “a visão e a percepção”, mas "inferência, julgamento, memória, reconhecimento, conhecimento, experiência, prática”), especialmente quando a abordagem deveria ser a dos processos de construção de sentido. Para a autora, a "recepção é uma atividade produtiva”, no que dialoga com a linguística, área para a qual todo leitor é ativo em seus processamentos. Assim sendo, pode-se presumir que os ambientes onde se lêem textos são importantes balizas para as expectativas, hipóteses e compreensões geradas pelo leitor.

Retornando às transposições, perguntamo-nos: A transposição de jornais de um display para outro os transforma em que objeto? Alteram-se os displays e disso decorre o quê? Para aqueles que consideram os jornais transpositivos uma aberração, trata-se de um problema. Para quem vê nos periódicos transpositivos uma etapa adaptativa, eis uma solução. Mais uma vez, é de utilidade a descrição de Bolter e Grusin (2000), para quem não se trata nem de aberração nem de adaptação, mas de remediação.

Como já mencionado aqui, Palácios (2002), Silva Júnior (2001) e Barbosa (2001) apontam Melinda McAdams (1995) como autora da expressão “modelo da metáfora" (jornalismo feito com base em "modelos claramente transpositivos, importados de suportes mediáticos anteriores”). Ribas (2004) e Dalmonte (2007) citam John Pavlik (2001), que elenca as fases pelas quais vem passando a produção do jornalismo para a web. Mielniczuk (2004) traz Pryor (2002), que propõe a periodização do jornalismo online em “ondas" que começam em 1982 e chegam a 2001. Canavilhas (2006) apresenta os quatro modelos da periodização de Cabrera Gonzalez (2000): fac-símile, sendo a "reprodução simples de páginas da versão impressa de um jornal, quer através da sua 
digitalização, quer através de um PDF”; modelo adaptado, em que "os conteúdos ainda são os mesmos das versões escritas”, mas “a informação é apresentada em layout próprio" (e começa a integração dos links); modelo digital, no qual se tem "layout pensado e criado para o meio online" e é obrigatório que exista hipertexto, espaço para comentários e notícias de última hora; modelo multimédia, em que se aproveita o máximo que o ambiente digital oferece (interatividade e hipermídia). Alguns pesquisadores brasileiros, como Mielniczuk (2001), Silva Júnior (2001) e Ribas (2004), propõem fases ou categorias de jornalismo feito para ser lido em telas. Em texto de 2003, Mielniczuk adota a expressão "geração" para tratar de tipos de webjornalismo. Embora talvez exista um desejo de agilidade na "reinvenção" do jornalismo para adequá-lo às possibilidades da web e das telas, não são os jornalistas que dão esse ritmo às mudanças. Se para o produtor é possível tratar de transposições, para o leitor, não é possível transpor experiências. Ele não se engana com aparências. O leitor aprende. Assim que entra em contato com algo que estava fora de seu "horizonte de expectativas", põe em riste a operação de comparar, como veremos na pesquisa que se passa a relatar.

\section{Materiais, método e instrumentos de pesquisa}

Esta investigação teve o objetivo de compreender a experiência do leitor na lida com um jornal impresso simulado, o JB Online, muito embora não tenhamos lidado com uma amostra representativa da população de leitores. Nosso intento era mesmo o de analisar situações localizadas de interação entre leitores e certo tipo de jornais online, daí problematizando aspectos da produção jornalística “em metáfora” dirigida ao leitor.

Convidamos um grupo de sete voluntários para navegar o Jornal do Brasil, no período de agosto a setembro de 2008. Procuramos encontrar leitores dispostos a participar da investigação, cujo perfil diferisse em relação à idade, à formação escolar e à experiência com jornais. Dos sete voluntários, dois tinham mais de 50 anos, eram leitores de jornais impressos e tinham pouquíssima experiência na rede. Ambos, um homem e uma mulher, eram aposentados, com formação superior. Outros dois usuários participantes eram recém-formados em cursos superiores tecnológicos, empregados em cargos administrativos de empresas privadas, leitores frequentes de jornais impressos e experientes em atividades na web. Os outros três leitores eram estudantes de graduação em engenharia, leitores de jornais na rede e fora dela. Nenhum dos voluntários conhecia a versão simulada do jornal, assim como nenhum deles tinha contato com o Jornal do Brasil online, que circula no estado do Rio de Janeiro, sendo a pesquisa desenvolvida em Minas Gerais. Os perfis desses indivíduos nos pareceram adequados à investigação, uma vez que encontramos neles elementos que variavam do jovem letrado digital (pouco afeito à leitura de impressos) até o leitor experiente de impressos (pouco afeito à leitura em ambiente digital).

Os jornais eram apresentados ao leitor, que devia navegar livremente, cabendo a ele determinar o momento de encerramento da leitura. Caso fizesse perguntas aos pesquisadores, estes estavam limitados a dar respostas curtas e a estimular que o usuário falasse, navegasse e tecesse comentários. 
O JB Online é um simulador da versão impressa do Jornal do Brasil ${ }^{6}$. Mesmo com essa aparência, a apresentação do periódico não pode dispensar tecnologias digitais para ser realizada. O JB Online foi desenvolvido em formato Adobe Flash Player, com recursos de controle. Para acessá-lo, o leitor precisa de um computador com browser e o plug-in compatível, como era nosso caso.

Utilizamos microcomputadores com o browser Mozilla Firefox 2.0, com plug-ins instalados, monitor de 15 " e conexão banda larga de 600kbps. Os pesquisadores registraram as ações e os comentários de cada leitor, incluindo expressão facial, corporal ou postura. Para auxiliar no registro dos testes, cada pesquisador utilizou gravadores de voz (MP3 ou analógico), software especializado (do tipo spyware) e anotações em caderno. Cada um desses registros foi transcrito e acrescido de análises e comentários.

Para geração de dados, empregamos o protocolo verbal, técnica que tem sido empregada em inúmeras pesquisas cujo objetivo é investigar processos de leitura. "Com base nos dados obtidos através da verbalização feita pelos participantes, o pesquisador faz inferências sobre os processos cognitivos subjacentes à compreensão do texto" (Tomitch, 2007: 46). Neste caso, não tínhamos como foco a compreensão dos textos que cada um escolhia para acessar ${ }^{7}$. Após a experiência dos leitores com os jornais, os pesquisadores faziam breve entrevista com cada um, abordando suas experiências na navegação/ leitura dos jornais.

\section{Resultados}

O quadro a seguir oferece uma visão panorâmica dos temas abordados pelos leitores durante os protocolos verbais. Os itens da coluna à esquerda foram levantados com base na análise das proposições presentes nas falas dos participantes. Dessa forma, após a transcrição dos protocolos verbais e a revisão das anotações feitas pelos investigadores, chegamos a um elenco de doze aspectos mais citados. Cada participante demonstrou incômodo ou manifestou algo em relação a esses elementos. A ausência do link nos textos das notícias, por exemplo, foi percebida pelos leitores mais jovens. A demora no carregamento das páginas foi mencionada por grande parte dos usuários. $\mathrm{O}$ processo de aprendizagem dos mecanismos do "aprender a folhear" as páginas virtuais causou estranhamento em quase todos os leitores, muito embora tenha sempre sido uma operação de sucesso.

\footnotetext{
${ }^{6}$ No caso de outro jornal brasileiro, o Estado de Minas, simulado na web, por exemplo, o argumento de venda pelo serviço de telemarketing tenta encantar o consumidor com a ideia de que "do jeito que você conhece o jornal impresso, de papel, você vai ver na tela, e até pode folhear, ouvir o barulho do papel, etc.”. Na página de login do jornal, lê-se: "Agora você vai poder ler o seu jornal na internet exatamente como você lê na sua casa. Poderá folhear todos os cadernos e ver as páginas como elas foram publicadas. É muito simples. Experimente agora!” Há um link para uma página de "degustação" e a imagem de um notebook sendo manipulado por uma mão de homem (de terno) que folheia as páginas.

${ }^{7}$ Em Ribeiro (2008), a autora distingue, por meio de testes com leitores, as práticas da navegação da compreensão leitora. $O$ foco do estudo que ora se relata recaía sobre a navegação, não tratando de aspectos da compreensão de textos.
} 
Quadro 1

Aspectos recorrentemente mencionados pelos leitores.

(a) identifica aspectos mencionados; (Ø) identifica não-mencionados.

\begin{tabular}{|c|c|c|c|c|c|c|c|}
\hline Elementos relevantes & Mauro & Rod & Giba & Ana & Luiz & Maria & Mário \\
\hline Link & $\emptyset$ & + & + & $\emptyset$ & $\emptyset$ & $\emptyset$ & + \\
\hline Carregamento & $\emptyset$ & $\emptyset$ & + & + & + & + & $\emptyset$ \\
\hline Simulação de flip & $\emptyset$ & + & + & + & + & $\emptyset$ & $\emptyset$ \\
\hline Aprendizado da operação & + & + & + & + & $\emptyset$ & + & + \\
\hline Corpo da fonte & $\emptyset$ & $\emptyset$ & + & + & + & + & + \\
\hline Máquina de busca & $\emptyset$ & $\emptyset$ & $\emptyset$ & + & $\emptyset$ & $\emptyset$ & + \\
\hline Sim e animação & $\emptyset$ & $\emptyset$ & + & $\emptyset$ & $\emptyset$ & $\emptyset$ & $\emptyset$ \\
\hline Feedback & $\emptyset$ & $\emptyset$ & + & + & $\varnothing$ & $\emptyset$ & $\varnothing$ \\
\hline Ancoragem no impresso & + & + & + & + & + & + & + \\
\hline Imagens & + & $\emptyset$ & + & $\emptyset$ & $\emptyset$ & $\emptyset$ & $\emptyset$ \\
\hline Varredura da página & + & + & $\emptyset$ & $\emptyset$ & $\emptyset$ & + & $\emptyset$ \\
\hline Anúncios e pop-ups & + & + & + & + & $\emptyset$ & $\emptyset$ & + \\
\hline
\end{tabular}

Dos recursos oferecidos, o mais marcante é a simulação do folhear das páginas do jornal impresso (flip). Como se o ponteiro do mouse fosse o dedo indicador do usuário, as pontas das páginas virtuais são tocadas e reagem como uma folha de jornal impresso. A leitura da página inteira é tarefa impossível sem a ferramenta de aproximação. Caso algo chame a atenção do leitor, ele deve usar a lupa para explorar a página. As ampliações são mostradas em nova janela do browser, na qual aparece o indicador do estágio do carregamento da página.

\section{Discussão}

A experiência de navegação na internet não garantia que os leitores deixassem de ter dificuldades nos testes. Dos usuários mais experientes, o que encontrou mais dificuldade foi Mário, que não identificou os atalhos para os cadernos de seu interesse, recorrendo assim à passagem de página por página, revelando, na falta de links diretos para as notícias, sua insatisfação com a interface.

Entre os itens apontados pelos usuários e considerados relevantes na experiência de leitura, destaca-se o fato de que todos os participantes ancoraram-se, em algum momento, em suas experiências com o impresso. Certamente, essas experiências acumuladas emergem, de forma seletiva, durante o contato com as notícias em tela. É isso o 
que faz com que a maioria dos leitores (cinco de sete) se sinta incomodada com a impossibilidade de aumentar o tamanho da fonte do texto, prática exclusivamente digital.

O conhecimento que cada leitor acumula será sempre convocado, em menor ou maior grau, no contato com textos e suportes inovadores. É esse conhecimento que os auxilia a desvendar os sentidos do texto, assim como reconhecer e aprender a lidar com as pistas e as formas de acessar seu conteúdo ou interferir nele. Luiz, por exemplo, compara: "É bom. Melhor do que jornal. Só que demora um pouco mais, não demora?”; E Rodrigo explica: "Não, mesmo quando eu compro um jornal normal eu faço justo isso. Tipo... eu vejo qual que é o título: 'PF implode megaquadrilha no MS', aí eu leio esse destaque, vejo as legendas das imagens, daí, se me interessar, eu leio tudo, ou passo direto. Isso pra qualquer tipo de jornal.”

O fato de o JBOnline fazer explícita referência a sua versão impressa faz emergirem comparações e julgamentos cuja base são jornais de papel. A explicitude dessa semelhança entre as interfaces, de certa forma, provoca a comparação e faz concluir que essas simulações estão aquém da experiência leitora, seja ela em papel ou em telas eletrônicas. As práticas dos leitores sugerem que navegar à procura de notícias traz expectativas obrigatoriamente relacionadas a outras experiências, sendo, portanto, impossível atribuir a algo a "originalidade". Em todos os casos, houve algum comentário que remetesse ao impresso, tecesse comparações ou fizesse julgamentos, como nos trechos citados anteriormente. $\mathrm{O}$ fato de esses jornais provocarem análises comparativas não se restringe a este tipo de proposta. Provavelmente, o parâmetro empregado por qualquer leitor para experimentar novos ambientes será seu histórico de práticas de leitura, mesmo em ambientes que tentam desfazer referências impressas. Esses parâmetros se entrecruzam e não são hierarquizados, sendo aplicados tanto do digital para o impresso quanto na mão contrária.

As situações desta pesquisa demonstram como a leitura provoca, mesmo em usuários menos experientes em ambientes digitais (e talvez principalmente neles), expectativas, hipóteses e inferências relacionadas a esse meio, sempre na relação com outros. Essas expectativas fazem parte do processamento da leitura. As expectativas estão ligadas a outras práticas de leitura com as quais o leitor esteve em contato ou das quais possui relativo conhecimento. Um usuário experiente de computador certamente já vivenciou situações que lhe permitem tirar conclusões sobre o que é possível realizar em ambientes digitais, tais como os comentários de Giba, que sabe: "Se eu conseguisse chegar aqui ó, clicasse aqui e isto aqui aparecesse, era vantagem", referindo-se à possibilidade de clicar na chamada de uma notícia; ou de Mário, que sugere: “Aí eu quero, por exemplo, ver a notícia de esportes... essa aqui. Agora, como faço pra ir pra lá? Poderia ter tipo um negocinho aqui assim, aí só clicar e ir direto na página.” A facilidade, a rapidez e o encurtamento de caminhos geram expectativas, que, no entanto, não são geradas apenas em usuários experientes.

A transposição, melhor dizendo, a tentativa de simulação de um jornal impresso em uma tela de tecnologia digital causa estranhamento justamente porque as expectativas dos leitores, sejam elas vagas ou precisas, não encontram correspondência no ato de ler. Do impresso para o digital, mesmo com o formato "transposto", os leitores, 
independentemente de sua proficiência, esperam contar com links, $p o p$-ups e recursos como copiar e colar, por exemplo. Um conhecimento mínimo sobre as possibilidades do ambiente digital influencia as expectativas e escolhas dos leitores, e não é à toa que Giba afirma que: "Se eu conseguisse chegar aqui ó, clicasse aqui e isto aqui aparecesse, era vantagem." Ele não faria uma observação como essa se estivesse diante de um jornal impresso, e só pode fazê-la quando emerge sua experiência variada nas práticas leitoras.

No ambiente digital, o usuário se incomoda com a "letra pequena”. O problema só se dissolve com o uso do mouse, que aciona uma ferramenta (a lupa) que simula um dispositivo analógico. Mário levanta a hipótese de que talvez a proposta funcione bem para leitores que gostam de jornais de papel. As práticas de Giba, no entanto, relativizam isso, já que o leitor não conseguiu identificar de imediato a primeira página do jornal e não lhe foi possível evitar o estranhamento diante desta experiência. Se ainda existe resistência de alguns leitores em relação à mediação do computador, ao que tudo indica, uma simulação não resolverá o problema.

Aumentar o corpo da fonte com o zoom é um bom indício de como as experiências digitais e analógicas são inextricavelmente diferenciadas. O formato do suporte altera as expectativas dos leitores e faz com que a "transposição" precise recorrer a ferramentas tipicamente digitais. Nesse ponto, a dificuldade dos usuários é compreensível. Leitores sem experiências digitais acionam o conhecimento que têm, mas ele não é adequado à experiência que terão, o mesmo ocorrendo do digital para o impresso.

\section{Considerações finais}

Quando um texto é materializado em determinado meio, as propriedades desse meio passam a compor as expectativas dos leitores. Quando tais expectativas não são cumpridas, há um descompasso inicial, mas o leitor, seja onde for, tende ao ajustamento. Mário, por exemplo, ao sentir falta do link, manifestou expectativas sobre ele, pois sabe que "o link facilita muito" e "acaba resumindo", conhece o recurso que atende, oportunamente, pela metáfora de "atalho".

A proposta de simular um jornal impresso em ambiente digital provoca, no máximo, a emergência de comparações mais óbvias entre práticas. Sequer é possível confundi-las, já que, rapidamente, os usuários se apercebem das peculiaridades da experiência. Nem mesmo a disposição dos textos, "idêntica" na tela e no papel, os faz "entrarem no jogo" da sensação de ler um jornal impresso. Movimentos e ações precisam ser alterados para que seja possível ler o jornal simulado.

No quadro dos estudos apresentados, o que são esses jornais: transpositivos, metafóricos ou web? A despeito de um primeiro impulso de classificar esse tipo de simulação como "transposição", essas "versões" são tudo isso e nada disso, ao mesmo tempo. A existência desses jornais e sua operação pelo usuário/leitor parecem desarranjar tal classificação, estanque demais para as possibilidades híbridas não dos jornalismos na rede, como produtos, mas para os processos leitores dos usuários.

A “mera transposição" de jornais impressos (na expressão de Mielniczuk) tem aparência similar à do JBOnline, especialmente no que diz respeito à diagramação. 
À primeira vista, aquelas páginas lembram a digitalização por scanner. No entanto, é impossível obter, na tela, os mesmos tamanho e resolução dos diários de papel. Só essa experiência já seria suficiente para abalar o leitor, não existissem ainda outras, como a programação em Flash, os sons e o movimento das páginas.

Clicando-se em uma matéria, acessa-se o conteúdo, que deve ser ampliado, após demorado download. Não há possibilidade de personalização, nem de instantaneidade, no sentido de que haja atualização constante das notícias. No entanto, há memória, caso se faça uma busca, e há acesso a edições anteriores. A interatividade, mesmo que "reativa” (Primo, 2000), emerge da necessidade de clicar aqui e ali para ir, voltar, ler, ampliar, buscar. Sem isso, não há leitura depois da primeira página. E ainda que não haja hiperlink por trás das palavras no texto, eles estão no clique das páginas, nas matérias inteiras e nas fotos.

Em última análise, mesmo que o $J B$ disponibilizasse versões escaneadas de todas as suas páginas, a experiência do leitor diante da tela, ao clicar a passagem das páginas sem som e sem movimento "de folha”, seria outra, não aquém nem além, mas certamente diversa da leitura do jornal impresso. Transposição, metáfora ou "terceira fase" desarranjam-se na experiência empírica do leitor. O que parece ocorrer, nesses casos, é que as possibilidades da tecnologia digital são empregadas para simular o papel, tratando-se, então, de uma “problemática" não de nomenclaturas, nem de "fases", mas de objetivos e pessoas.

Se nosso objetivo aqui era analisar as experiências de um grupo de leitores na interação com jornais online que simulam suas versões impressas, ao que parece, tal simulação no ambiente digital é uma experiência curiosa e rica, especialmente porque aciona hipóteses e expectativas múltiplas no leitor. A despeito de dizerem que o leitor foi passivo um dia (até que os norte-americanos o reinventassem), as operações cognitivas de seleção, generalização, comparação, construção de referências, parâmetros e ajustes finos mostraram-se mobilizadas e vivas, mesmo quando executadas em telas estreitas e pouco conhecidas para estes leitores.

É preciso admitir, no entanto, que, a despeito das muitas leituras que este tipo de estudo permite e de seu caráter planejadamente qualitativo, seus limites são claros, sendo um deles a não-representatividade da amostra de usuários participantes, além da leitura de apenas um jornal com proposta "metafórica". Para conhecer melhor as práticas de interação leitor/jornal há ainda muito espaço para estudos mais amplos e mais aprofundados.

\section{Referências bibliográficas}

Barbosa, S. (2001) 'Jornalismo Online: dos Sites Noticiosos aos Portais Locais', XXIV Congresso Brasileiro de Ciências da Comunicação (Intercom), Campo Grande (MS), Setembro.

Bolter, J. D. e Grusin, R. (2000) Remediation Understanding New Media, USA: MIT Press.

Canavilhas, J. M. (2003) 'Webjornalismo: Considerações Gerais sobre Jornalismo na Web', I Congresso Ibérico de Comunicação [http://www.bocc.ubi.pt/pag/_texto.php3?html2=canavilhas-joao-webjornal. html, acessado em 12/7/2007].

Canavilhas, J. M. (2006) 'Do jornalismo Online ao Webjornalismo: Formação para a Mudança', 2006 [www. bocc.ubi.pt, acessado em 12/8/2007]. 
Chartier, R. (2001) 'Textos, Impressão, Leituras' in Hunt, L. (2001) A Nova História Cultural, São Paulo: Martins Fontes, 211-138.

Dalmonte, E. F. (2007) 'O Webjornalismo Enquanto Bem de Experiência: do Receptor ao Leitor Participante', IX Congresso Brasileiro de Ciências da Comunicação da Região Nordeste.

Ferreira, A. B. H. (2004) Novo Dicionário Eletrônico Aurélio Século XXI, São Paulo: Positivo.

Fidalgo, A. (2003) 'Sintaxe e Semântica das Notícias Online: Para um Jornalismo Assente em Base de Dados' [www.bocc.ubi.pt acessado em 15/4/2009].

Houaiss, A. (2001) Dicionário Eletrônico Houaiss da Lingua Portuguesa, Rio de Janeiro: Objetiva.

Kress, G. e Van Leeuwen, T. (1998) 'Front Pages: (The Critical) Analysis of Newspaper Layout' in Bell, A. e Garret, P. (eds.) Approaches to Media Discourse, USA: Blackwell Publishing, 186-219.

Kress, G. e Van Leeuwen, T. (2001) Multimodal Discourse. The Modes and Media of Contemporary Communication, London: Hodder Arnold.

Kress, G. e Van Leeuwen, T. (2006) Reading Images. The Grammar of Visual Design, London: Routledge.

Mielniczuk, L. (2001) 'Características e Implicações do Jornalismo na Web', II Congresso da SOPCOM, Lisboa [http://www.facom.ufba.br/jol/pdf/2001_mielniczuk_caracteristicasimplicacoes.pdf, acessado em $15 / 12 / 2006]$.

Mielniczuk, L. (2003) 'Sistematizando Alguns Conhecimentos sobre Jornalismo na Web' [www.bocc.ubi.pt, acessado em 3/1/2006].

Mielniczuk, L. (2004) 'Webjornalismo de Terceira Geração: Continuidades e Rupturas no Jornalismo Desenvolvido para a Web', XXVII Encontro dos Núcleos de Pesquisa da Intercom.

Moherdaui, L. (2005) O Usuário de Notícias no Jornalismo Digital - Um Estudo sobre a Função do Sujeito no Último Segundo e no A Tarde Online. Dissertação de Mestrado em Comunicação e Cultura Contemporâneas, Faculdade de Comunicação, Salvador: Universidade Federal da Bahia.

Moraes, A. (2008) 'A Forma da Notícia' in Felippi, A., Soster, D. A. e Piccinin, F. (orgs.) Edição de Imagens em Jornalismo, Santa Cruz do Sul: Edunisc, 241-251.

Natansohn, L. G. (2007) 'O Que Há e o Que Falta nos Estudos sobre Recepção e Leitura na Web?', Revista da Associação Nacional dos Programas de Pós-Graduação em Comunicação - E-Compós, 10: 1-16.

Norman, D. (1999) 'Affordance, Conventions and Design', Interactions, may: 38-42.

Norman, D. (2006) O Design do Dia-a-Dia, Rio de Janeiro: Rocco.

Nosengo, N. (2008) A Extinção dos Tecnossauros, Campinas, SP: Editora Unicamp.

Palacios, M., Mielniczuk, L., Barbosa, S., Ribas, B. e Narita, S. (2002) 'Um Mapeamento de Características e Tendências no Jornalismo Online Brasileiro', XXV Congresso Anual em Ciência da Comunicação.

Pereira, F. H. (2003) O Jornalista On-Line: Um Novo Status Profissional? Uma Análise sobre a Produção da Notícia na Internet a Partir da Aplicação do Conceito de 'Jornalista Sentado'. Dissertação de Mestrado em Comunicação, Brasília: Universidade de Brasília.

Pina, P. K. da C. (2005) 'O Jornal e a Leitura no Oitocentos Brasileiro', V Encontro dos Núcleos de Pesquisa da Intercom, 5 a 9 de Setembro.

Primo, A. (2000) 'Interação Mútua e Reativa: Uma Proposta de Estudo', Revista da Famecos, 12: 81-92.

Ribas, B. (2004) 'Características da Notícia na Web - Considerações sobre Modelos Narrativos', II Encontro Nacional de Pesquisadores em Jornalismo - SBPJor, FACOM/UFBA, Salvador.

Ribeiro, A. E. (2008) Navegar Lendo, Ler Navegando - Aspectos do Letramento Digital e da Leitura de Jornais. Tese de Doutorado em Estudos Linguísticos, Linguagem e Tecnologia, Faculdade de Letras, Belo Horizonte: Universidade Federal de Minas Gerais.

Ribeiro, A. E. (2009) 'Notas sobre o Conceito de 'Transposição' e suas Implicações para os Estudos da Leitura de Jornais On-Line, Em Questão, 2: 15-30.

Silva Júnior, J. A. da (2001) 'A Relação das Interfaces enquanto Mediadoras de Conteúdo do Jornalismo Contemporâneo: Agências de Notícias como Estudo de Caso' [www.bocc.ubi.pt, acessado em: 3/1/2006].

Teberosky, A. e Colomer, T. (2003) Aprender a Ler e a Escrever. Uma Proposta Construtivista, Porto Alegre: Artmed.

Tomitch, L. M. B. (2007) 'Desvelando o Processo de Compreensão Leitora: Protocolos Verbais na Pesquisa em Leitura', Signo, 53: 42-53.

Zamith, F. (1999) 'Dos Jornais-Fax de Moçambique aos Web-Jornais', III Lusocom - Encontro Lusófono de Ciências da Comunicação, Universidade do Minho, Braga, 28 de Outubro. 